\title{
Selective Regional Policy of the State: Theoretical Bases and the World Experience of Realization
}

\author{
Olga V. Sidorenko \\ Khabarovsk State Academy of Economics and Law, Russian Federation
}

Inna S. Khvan

The Russian Presidential Academy of National Economy and Public Administration, Far Eastern branch, Russian Federation

Email: iskhvan@mail.ru

Doi:10.5901/mjss.2015.v6n3s5p41

\begin{abstract}
In the article the theoretical fundamentals of selective regional policy, developed by the authors as an independent type of regional policy of the state are presented. Classification of the types of selective regional policy of the state is offered. Classification of the instruments of selective regional policy of the state is developed. An existence of common features in the realization of selective regional policy in the foreign countries at the end of the XX century is shown.
\end{abstract}

Keywords: regional economic policy, selective regional policy, methods of regional policy, regional differentiation, polarizing selective policy, leveling selective policy

\section{Introduction}

Questions of a choice of the priorities of regional development, methods of realization of the regional economic policy at different stages of development of the national economies are a subject of discussions, both on the theoretical, and on the practical level in the majority of developed countries of the world. The variety of national features accumulates on one of the key problems of modern regional economic science - the absence of conventional theory of the regional economic policy of the central government.

The world practice shows that for the purpose of smoothing of interregional distinctions the state pursues selective policy concerning, first of all, the regions which are lagging behind in development. However the standard interpretation of the term 'selective policy' still does not exist, still in the regional science its role in the state regulation of territorial development isn't determined. The problem becomes complicated that in the practice of realization of the regional economic policy the objects of selective influence are not only the regions, which are lagging behind in development, but also the overpopulated areas, and also the developed regions. Thus, there are the questions of need and focus of the selective impact of the state on the regional development.

The purpose of the article is the development of theoretical and methodological provisions of selective regional policy of the state and synthesis of the world experience of its realization.

\section{Theoretical Approaches to the Determination of Selective Regional Policy of the State}

Generalization of the scientific views allows give two main approaches to understanding of the role and the place of selective support in the regional economic policy of the state. In first approach, it is identified with the regional economic policy of the state (Armstrong \& Taylor, 2000); in second, it is considered as a component of the regional economic policy of the state (Samuels, 1983; Shvetsov, 2009).

Within the first approach, it is considered that "selective support of the regional development cannot be referred to the actually macroeconomic or microeconomic regulators, as for its realization practically all instruments of economic policy" can be used (Mikheeva, 2000, p.145). From this statement it is not clear, than selective support differs from the actually regional policy.

In the report on joint research of the Expert institute (Russia) and the Center for studying of Russia and the Eastern 
Europe of the University Birmingham (Great Britain), made within the TASIS program "Economic reforms in Russia: regional aspect" it is noted that "the essence of federal regional policy consists in selective support of these or those regions" (Artobolevsky, 1996, p. 106), that is the authors of research also identify the state regional policy and selective support, that in our opinion, is not absolutely correct as the circle of questions, resolved within the state regional policy are much wider.

Within the second approach the researchers give two forms of participation of the state in development of the regions: the main (constant) and additional (temporary) (Larina, 2000). According to the scientist, selective influence of the state in the solution of social, economic, environmental and other problems represents a form of additional participation in the regional development, however N. I. Larina doesn't call it selective regional policy. In her further works the greatest attention is paid to studying of the main form of participation of the state which is carried out "by the means of formation of multilevel spatial structure of the government and distribution of the state functions between different levels" (Larina, 2005, p.12).

In our opinion, the term 'support' in the system of regional economic policy is not absolutely correct as the support assumes only the help for solution of the regional problems, but doesn't create the opportunities for further regional development of the territories. According to the author, the term 'support' assumes assistance to the regions for the purpose of ensuring equal access for the population of the needing region to the budgetary services, guaranteeing the realization of constitutional rights of the citizens. Selective support to the needing regions represents only a part of selective regional policy of the state.

As the objects of selective (selective) regional policy can act not only the problem regions, but also the developed regions. In our opinion, the choice of the objects of selective regional policy depends on the purposes of the state regional policy which, form two models of regional economic policy - 'efficiency' and 'equality' (Armstrong \& Taylor, 2000).

Generalizing the above said, we will note that further we will understand the system of conscious measures which are carried out by the state bodies, directed on creation of the institutional environment of the regional development and realization of the purposes of spatial development of the country proceeding from the public priorities of the state at this stage of development as the regional economic policy.

In our opinion, the content of regional policy of the state consists in the coordinated realization of two of its independent types: common regional and selective.

Measures of the common regional policy have no selective appointment and evenly influence on the all regions of the country. This policy is directed on creation of the general prerequisites of regional development. It forms the economic, organizational and legal environment of independent activity of the all regions. Creation of the legal, economic and organizational forms of impact on the process of social and economic development of the regions is the institutional base of regional development. Therefore, it is difficult to disagree with the opinion of the academician Minakir (2001), that the role of federal center has to consist in creation of such common regional institutional conditions that would not exclude, and, on the contrary, promoted the effective development of regional initiative in the field of institutional construction. Institutional environment of the long-term regional development includes creation and functioning of the system of standard and legal institutes; the system of financial and budgetary and administrative institutes.

Selective regional policy, being an independent type of regional economic policy of the state, is formed proceeding from the public purposes and priorities designated in the concept of territorial development of the country that sets the strategic reference points of spatial development.

Selective regional policy represents a specific form, a special case of manifestation of selectivity of the state economic policy. In the developed countries, purposeful selective intervention of the state in the processes of regional development begins when the spatial social and economic disproportions become excessive (the last are considered as the inevitable negative consequences of activity of the market mechanisms).

The process of development of selective regional policy of the state demands the solution of problem of the reasonable choice of the system mechanisms. In this regard, there is a need of justification of methodological principles of selective impact of the state on the regional development, representing a methodological basis of formation of selective regional policy of the state. According to the authors of this article, the system of mechanisms of the selective regional policy can be productive only by the support on a set of following methodological principles:

- the principle of focus means that the selective regional policy is directed on achievement of the accurately put goal as management of the system is recognized to provide its purposeful behavior under the changing conditions;

- the principle of selectivity opens the main content of selective regional policy as an independent type of regional policy of the state and means that the selective regional policy influences not on the all regions of the 
country but only on the certain territories ('engines of growth', problem regions), that is the management process is carried out selectively;

- the principle of addressing means that the realization of selective regional policy of the state assumes an address impact on development of the concrete region;

- the principle of alternativeness of the selective regional policy is connected with the possibility of development of the national economy and its separate links - regions on different trajectories, at different interrelations and structural ratios. When forming the selective regional policy of the state there is a need of creation of alternatives, i.e. determination of the possible qualitatively different scenarios of the selective regional policy.

- the principle of rationality means that when developing the selective regional policy it is necessary to choose the most acceptable (rational) scenario of its realization at this historical stage of development of the state.

- In the principle of rationality the dialectics of selective regional policy of the state which consists in finding of a compromise between the support of both the problem regions, and the regions - 'engines of growth', but also in the case of support of the branches - 'growth poles' in the problem regions of the country is reflected.

- the principle of preservation of territorial integrity is connected with the understanding of territorial space of the country as the economic system. The feature of any economic system is its internal heterogeneity. Heterogeneity of economic space has considerable impact on the structure and efficiency of the economy, strategy and the tactics of institutional transformations and the social and economic policy. Therefore, the question of increasing or decreasing of heterogeneity of the economic space is of great importance from the point of view of its influence on territorial integrity of the country.

The natural levels of territorial distinctions are considered socially useful as they bring dynamism in the economically and socially caused placement of the places of application of work, capital.

Considerable distinctions in the level of development of the territories are qualified negatively. The developed regions, owing to the best condition of the infrastructure, higher compensation, the low social tension begin to attract more and more intensively the capital and the most mobile, professionally prepared manpower from the regions with the low level of social and economic development. As a result, the economic situation in the territory of problem regions worsens, the social tension grows. At the same time, dissatisfaction of the developed regions in connection with an increase of work in the solution of the nation-wide tasks, including, on rendering the economic help to the problem territories grows. Economic contradictions between the developed regions and the problem regions create the threat to the country's unity and interfere to the social and economic development of the country in general.

The content of the principle of preservation of territorial integrity is that the selective regional policy has to be directed on rapprochement and merging of the regional economies in the uniform complete system, by the means of interregional integration. This principle is closely connected with the principle of providing economic security of the country. The principle of providing economic security means that the selective regional policy has to be directed on creation of the conditions for achievement of the steady economic growth in the regions and countries in general, and also protection of the economic interests at the national and international levels.

Generalizing the aforesaid, the selective regional policy in the work is understood as a selective impact of the state bodies on the certain territories by the means of rational distribution of economic activity on the territory of the country for the purpose of increasing of the level of its social and economic development and the preservation of territorial integrity.

\section{Classification of the Types of Selective Regional Policy of the State}

Depending on the object of influence the authors develop the classification of types of selective regional policy (table 1). The polarizing selective regional policy provides the priority support of one or several separated regions having the highest economic and investment potential to the detriment of other regions. Realization of this type of selective regional policy allows provide the inflow of investments into the separated regions of the country which as a result can act as the main 'locomotives' for the accelerated development of economy of the all country. In turn, the state economic growth as a result leads to the gradual economic recovery and the backward regions. Thus, this type of selective regional policy is based on the principles of nodal system and on the prerequisite about existence in the regions of the areas generating their progress for the purpose of maximizing the national income. 
Table 1. Comparative characteristic of the types of selective regional policy of the state

\begin{tabular}{llll}
\hline \multicolumn{1}{c}{ Features } & \multicolumn{1}{c}{ Polarizing selective policy } & \multicolumn{2}{c}{ Eguilizing selective policy } \\
\cline { 2 - 4 } Objects of selective policy & $\begin{array}{l}\text { Regions with the greatest } \\
\text { potential for economic growth }\end{array}$ & Rural areas and backward regions & $\begin{array}{l}\text { Congested urban } \\
\text { agglomerations - megalopolises }\end{array}$ \\
\hline \multirow{2}{*}{ Aim of selective policy } & $\begin{array}{l}\text { Achieving maximum national } \\
\text { welfare through the effective use } \\
\text { of the economic potential of } \\
\text { regions - growth poles }\end{array}$ & $\begin{array}{l}\text { Reducing regional disparities by } \\
\text { encouraging the growth of backward } \\
\text { regions and rural areas }\end{array}$ & $\begin{array}{l}\text { Reducing regional disparities by } \\
\text { restraining the growth of } \\
\text { megalopolises }\end{array}$ \\
\hline General principles & Principles of nodal system & Principles of social justice & \\
\hline
\end{tabular}

The state's impact on the developed regions is directed on the stimulation of internal areas of the largest agglomerations (Bajpai \& Sachs 2000) and implementation of the large-scale programs of development of the territories. The polarizing selective regional policy really can provide advancing growth of the national economy, but due to strengthening of the property and social stratification of the population. Such approach is used usually by the developing countries, and the most striking example of its realization - China.

The leveling selective regional policy represents the policy of alignment of the levels of economic development and investment potentials of the country's regions. The objects of this type of selective regional policy are the problem regions. The choice of the regions that have to become the objects of the leveling selective regional policy is a complex problem, which is solved by each country independently.

In the majority of countries with the developed market economy as the objects of selective policy directed on alignment of the levels of economic development of the regions, at least, three types of regions are separated: depressive industrial regions; depressive agrarian regions; overpopulated city areas.

Respectively, it is possible to speak about the character of the leveling regional selective policy. In a case, if the objects of leveling selective regional policy are the overpopulated city areas - megalopolises, one say about the restraining character of the leveling selective regional policy.

In a case when the objects of the leveling selective regional policy are the regions that are lagging behind in development, it is possible to speak about its stimulating character. The stimulating character of the leveling selective regional policy is shown in stimulation of the inflow of investments into the backward regions and providing financial aid to the last. This approach is characteristic mainly for the economically developed countries.

The stimulating and restraining selective regional policy are based on the general principle of social justice, that is such spatial distribution of economic activity at which the inhabitants of all regions have the approximately equal opportunities of achievement of desirable welfare.

The purposes of stimulating selective policy are: alignment of the level of economic and social development of different parts of the country, reduction of the number of problem regions, solution of the problems of development of the problem regions.

In case of realization of the restraining selective policy social justice is provided with the control (restriction) of growth of economic potential of the city agglomerations. The example of constraining policy is the realization of regional policy in France, Great Britain, Japan, the Netherlands (Sidorenko, 2010).

Stimulating selective policy of the problem regions is directed on the realization only of such purposes, which cannot be reached automatically as a result of action of the market mechanisms. According to the authors, the selective policy of social and economic development of the problem territories differs from the other measures of the state regulation of territorial development (for example, from the absolutely depersonalized grants) in an obligatory address and target orientation.

Coming from the developed theory-methodological provisions of selective regional policy, on the nature of selective impact on the object the author allocates two groups of instruments: limiting the economic development of the region and stimulating its development.

In the world practice, there are two types of development of the regions: exogenous development (development at the expense of external factors) and endogenous development (development at the expense of internal factors) (table 2).

The offered classification of instruments of the selective regional policy, allows determine, unlike the known classifications, the nature of selective impact of the state on the endogenous and exogenous type of regional development.

Exogenous (external) development of the territories (objects of selective regional policy) is carried out at a strong 
external intervention from the government bodies of the power. Orientation to the endogenous economic development, i.e. mainly on the internal sources of development, happens by the indirect state intervention.

The stimulating instruments of regional development are used in case of carrying out the selective policy both polarizing, and leveling. The difference consists only in the objects of selective influence: polarizing regional policy is directed on stimulation of the developed regions that are 'the growth points' of national economy, by application of the leveling regional policy as the object of stimulation are the depressive and backward regions.

Table 2. Classification of instruments of the selective regional policy depending on the nature of impact on exogenous and endogenous types of the regional development

\begin{tabular}{|c|c|c|}
\hline & Stimulating instruments & Limiting instruments \\
\hline 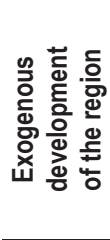 & $\begin{array}{l}\text { State investment in the construction of industrial and social } \\
\text { infrastructure. } \\
\text { State backing. } \\
\text { State order (public purchases). }\end{array}$ & $\begin{array}{l}\text { Toughening up of legal regulations in the field of land } \\
\text { use, environmental protection, urban planning } \\
\text { Bounties for the decentralization of industry. } \\
\text { Construction embargo of new industrial enterprises and } \\
\text { the expansion of existing } \\
\text { Introduction of «certificates of industrial development » } \\
\text { Isolation public enterprises from big cities }\end{array}$ \\
\hline 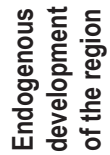 & $\begin{array}{l}\text { Providing different types of preferences (customs, tax, } \\
\text { administrative), soft loans, rights of accelerated depreciation for } \\
\text { entrepreneur in the region. } \\
\text { Creation of special economic zones, industrial parks (grounds). }\end{array}$ & $\begin{array}{l}\text { Increases in tax rates for the lease of land in congested } \\
\text { agglomeration } \\
\text { Introduction of taxes on the construction of enterprises } \\
\text { Raising taxes for nature management }\end{array}$ \\
\hline
\end{tabular}

The limiting instruments are used only when carrying out the leveling policy as which objects the overpopulated city agglomerations are: Paris and Lyon (France), London and Birmingham (Great Britain), Tokyo (Japan), Helsinki (Finland), etc. Mainly administrative decisions belong to the instruments limiting exogenous development of the region: ban, penalties, permissions.

The instruments limiting endogenous development of the region are directed on the indirect control of placement of the enterprises in agglomerations, as a rule, these are the instruments of tax policy. For example, increase of the tax rates on land, including 'the penalty area': the closer to the center of Paris, the rate is higher; introduction in Finland of a special tax on investments into the construction.

It should be noted that the programs of regional development act as one of the most active stimulating methods of selective regional policy and represent a set of instruments directed on stimulation of the both endogenous and exogenous type of regional development. The striking examples of successful realization of the program method of regional development in the world practice are: 'The Tennessee' and 'The Appalachians' programs in the USA, 'The Southern Limburg' program in the Netherlands, 'The Pilbara - 21' program in Australia.

\section{Stages and Regularities of the Development of Selective Regional Policy of the State in Different Countries}

The authors of the article give four stages of the realization of selective regional policy in the world (Sidorenko 2011). At the first stage, the selective regional policy was created as the leveling stimulating. The objects of such policy were the less developed, backward regions, the main goal - decrease in interregional distinctions. Among the most known projects of initial stage is the program of development of the region of the valley of the river Tennessee (Tennessee Valley Authority Act. 1933), formation of the uniform body for streamlining of industrial development of the Ruhr region in Germany (Titze, 2007).

In the north of Sweden in 1920 - the $1930^{\text {th }}$ creation of 'the territories on bogs' - special agricultural colonies - for overcoming of the consequences of the world economic crisis by an increase in employment and the release of agricultural production was stimulated (Bylund, 1969). In Great Britain in 1933 for carrying out the anti-crisis policy 'special areas' were allocated, and in 1934 the first special law regulating development of the territories was adopted. During the pre-military period (the end of the $30^{\text {th }}$ of the XX century), the stimulating selective policy for undeveloped territories gained its development. So, for example, in Sweden different subsidies were received by the colonists founding the settlements specializing on production of the light industry (Sidorenko \& Leonov, 2011).

The main objective of the post-war period of the West-European countries was recovery of the economy of the 
regions which are most injured during the World War II: in the Netherlands the period of restoration 1945-1951 (Bylund, 1969); in Norway right after release of the country from the fascist troops the modernization of rural territories, especially on the Far North began.

The second stage of realization of the selective regional policy begins in the second half of the $50^{\text {th }}$ of the XX century. It is characterized by a variety of choice of the objects and instruments of selective influence of the state. For this period application of the not only stimulating (the USA, Canada, Sweden, the Netherlands, etc.), but also the constraining selective policy - France and Great Britain is characteristic. The striking example of restraining selective policy is 'the English' form of control over the placement of capacities of London and Birmingham in the form of so-called 'certificates of industrial development', representing some kind of permission to the new construction in the most safe regions with a high density of production and with the indicators of economic dynamics higher than the middle-national.

In the Asian countries to the middle of the $1950^{\text {th }}$, the selective regional policy wasn't conducted. Emergence of the interest to it in 1960 - the $1970^{\text {th }}$ years was caused by an aggravation of social and economic problems, as well as in the West-European countries in 1930 - the 1940th years. The ecological crisis in Tokyo and in the other huge cities in the early seventies, which coincided with the adverse economic conditions became incentive of the use of selective regional policy. The industry doing 'the public harm' began to be taken out on the periphery of the large city agglomerations to the rural areas, transformation of the centers of suburban and low-developed areas into the important economic kernels was stimulated (Volsky \& Kolovos, 1975). It is necessary to emphasize that at the beginning of the $60^{\text {th }}$ not only Japan, but also many other countries, began to pursue polarizing selective policy which was based on the principles of nodal system and on the prerequisite about existence in the regions of peculiar 'poles' generating their progress.

The third stage of realization of the selective regional policy is characterized by the change of accents of the leveling selective policy from the exogenous state regulation of the territories on stimulation of endogenous capacity of the problem regions. This regularity is shown and now. The governments of the majority of countries made the decision to refuse the large-scale national and regional programs and to concentrate attention on the local programs of arrangement of the territories. During this period, the main emphasis was placed on every possible development of innovative functions and the sphere of research and development of the problem regions, which in turn could attract the enterprises of the knowledge-intensive industries. In all developed countries during this period, the practice of creation of scientific parks or technopolises gained the development (Tatsuno, 1989).

The feature of the third stage of realization of the selective regional policy is its most active formation and realization in the Asian countries (Japan, South Korea, and China). Here the polarized selective regional policy was widely adopted. For example, South Korea preferred the concept of 'growth poles', the emphasis was placed on the development of Seoul and Busan; in China in 1979 the concept of "uniform placement of productive forces" was officially replaced with the concept of "use of comparative advantages", the preference was given to the regions having the greatest potential of economic growth (seaside regions) (Bajpai \& Sachs, 2000, p. 21).

The fourth stage of realization of the selective regional policy was marked by signing of the Maastricht agreements in 1993 that gave a basis of implementation of new 'supranational' regional policy within the European Union and to the development of integration processes (transformation of 'Europe of the national states' into 'Europe of the regions'). The analysis of the fourth stage for which globalization of the world economy and strengthening of the competition between the countries are characteristic, that is generally between the largest ('global') cities, allowed the author reveal the second regularity of realization of the selective regional policy - the policy of unloading of the city agglomerations began to contradict the national interests (The Brixton disorders 10-12 April 1981. London: HMSO, 1982), undermining competitiveness of the European countries in the world therefore there was a transition to the policy of selective stimulation of the large cities. Examples of the Netherlands (Ranstadt), Great Britain (the project of reconstruction of the London docks) are very indicative.

The growth of interregional distinctions in the foreign countries, and also expansion of a number of the countries of participants of the EU, promoted distribution in the society of ideology of 'the state of general welfare' that led to emergence of the third regularity - to the change of the polarized type of selective regional policy on the leveling. So, the purpose of the third national plan of territorial development of South Korea (the 1990 $0^{\text {th }}$ ) was the balanced development with a rate on the small and average cities of peripheral areas, in Japan the main idea of creation of technopolises was changed - they began to carry a social orientation with the emphasis on development of the local features, in China - the government modified the selective regional policy of the country, having concentrated on the problem of alignment of the regional disproportions (Plan of Revitalizing Northeast China, 2007). 


\section{Conclusions}

Summarizing, we will note that in this research:

1) The theoretical and methodological provisions of formation of selective regional policy of the state, including the development of conceptual framework, classification of its types, justification of the purposes, objects, methodological principles allowing consider the selective regional policy as the independent type of regional policy of the state that develops the theory and methodology of selective impact of the state on the regional development are developed.

2) The two-criteria classification of the instruments of realization of the selective regional policy allowing determine, unlike the known classifications, the limiting and stimulating nature of selective impact of the state on the endogenous and exogenous type of regional development when developing the mechanism of realization of the selective regional policy of the state is developed.

3) Classification of types of the selective regional policy which on the object of influence is subdivided on the leveling and polarizing, and on the nature of influence - on stimulating and constraining that supplements the theory-methodological provisions of selective impact of the state on the regional development is given.

4) Regularities of the realization of selective regional policy in the developed countries consisting in the change of its types and instruments are revealed: as a result of globalization of the world economy the constraining policy for the city agglomerations is replaced by the stimulating; the growth of interregional distinctions and distribution in the society of ideology of 'the state of general welfare' led to the change of polarizing policy with the leveling; in the instruments of realization of the leveling selective policy the change of emphases from the exogenous development of the problem territories on stimulation of their endogenous potential that is explained by reduction of the state resources aimed at the development of these regions is noted.

\section{References}

Armstrong, H., \& Taylor, J. (2000). Regional economics and policy. Oxford: Blackwell.

Artobolevsky, S. (1996). State regulation of the development of depressed areas in developed countries. Federalism and regional policy: problems of Russian and foreign experience: Collection of scientific papers, 3, 232-244.

Bajpai, N., \& Sachs, J.D. (2000). Foreign direct investment in China: issues and problems. Development Discussion Papers, 759. The Harvard Institute for International Development.

Bylund, E. (1969). Industrial location policy and the problems of sparsely populated areas in Sweden. Proceedings of a conference "Backward areas in advanced countries" held by the international economic association, London, Melbourne, Toronto, New York.

Larina, N. (2000). Change of the paradigm in the regional policy. Region: economics and sociology, 4, 3-22.

Larina, N. (2005). State regulation of regional development: World, Russia, Siberia. Novosibirsk: Institute of economy and industrial engineering.

Mikheeva, N. (2000). Regional economics and administration. Khabarovsk: RIOTIP.

Minakir, P. (2001). Transformation of regional economic policy. Economics of Contemporary Russia, 1, 34-47.

Plan of Revitalizing Northeast China (2007). [Online] Available: http//chinaneast. xinhuanet.com/2007-12/19/content_11981590.htm (February 25, 2015).

Samuels, R. (1983). The politics of regional policy in Japan: localities in corporated? New York.

Schvetcov, A. (2009). System experience of the regional policy. Problem analysis and administrative projecting, 2.

Sidorenko, O. (2010). Foreign experience of selective regional policy of state. Initiative of the XXI century, 2, 40-43.

Sidorenko, O. (2011). Classification tools of selective regional policy. Proceedings of the Irkutsk State Economic Academy (Baikal State University of Economics and Law), 5.

Sidorenko, O., \& Leonov, S. (2011). Foreign experience of the regional administration. Khabarovsk: Khabarovsk State Academy of Economy and Law.

Tatsuno, Sh. (1989). Strategy techno. Moscow: Progress.

Tennessee Valley Authority Act. (1933).

The Brixton disorders, April 10-12, 1981 (1982). London: HMSO.

Titze, M. (2007). Strategien der neuen Bundesländer im Rahmen der Gemeinschaft saufgabe "Verbesserung der regional Wirtschafts struktur". [Online] Available: http://edoc.bibliothek.unihalle.de/servlets/MCRFileNodeServlet/HALCoRe_derivate_00001507/1407.pdf (February 20, 2015).

Volsky, E., \& Kolovos, Ya. (1975). State regulation of the distribution of productive forces in the capitalist and developing countries. Moscow: Thought. 
